\title{
DEVELOPMENT OF SPECIALTY COATED FABRICS FOR CANOPY OF INFLATABLE MILITARY TENT (IMT) FOR FOREST AREA
}

\author{
Biswa Ranjan Das ${ }^{* 1}$ 《 iD , Dasaradhan Bharathi 1, Deepak Kumar Yadav 1, Manoj \\ Kumar Singh 1, Thako Hari Goswami 1, Namburi Eswara Prasad 1 \\ ${ }^{* 1}$ Defence Materials \& Stores and Research \& Development Establishment (DMSRDE), G. T. Road, \\ Kanpur-208013, Uttar Pradesh, India
}

DOI: https://doi.org/10.29121/granthaalayah.v9.i2.2021.3387

Article Type: Research Article

Article Citation: Biswa Ranjan Das, Dasaradhan Bharathi, Deepak Kumar Yadav, Manoj Kumar Singh, Thako Hari Goswami, and Namburi Eswara Prasad. (2021).

DEVELOPMENT OF SPECIALTY COATED FABRICS FOR CANOPY OF INFLATABLE MILITARY TENT (IMT) FOR FOREST AREA. International Journal of Research GRANTHAALAYAH, 9(2), 81-92. https://doi.org/10.29121/granthaa layah.v9.i2.2021.3387

Received Date: 02 February 2021

Accepted Date: 24 February 2021

Keywords:

Canopy

Coated Fabric

Inflatable Military Tent

Waterproof

Weather Resistance

\section{ABSTRACT}

The principal objectives of this present work were to develop novel coated fabrics in olive green (OG) colour to serve as canopy for inflatable military tent (IMT) for forest area. Two varieties of coated fabrics were developed by coating of specific grade aliphatic thermoplastic polyurethane (TPU) on Nylon fabrics and one more with coating of plasticized polyvinyl chloride (PVC) on Polyester fabric. The construction parameters and properties of the substrate basic fabrics used for coating were evaluated and reported. The various functional parameters such as breaking strength and elongation\%, tear strength, bursting strength, waterproofness, flame retardancy, flexing, accelerated ageing $\left(-40^{\circ} \mathrm{C}\right.$ and $70^{\circ} \mathrm{C}$ ), blocking, ultraviolet (UV) radiation protection and colour fastness to washing and light of the coated fabrics were measured and reported with details, along with an elaborate note on the preparatory process pursued for the development of these coated fabrics. The most suitable coated fabric for canopy of IMT was selected based on the evaluated functional features. Further, the thermal analysis was carried out for the selected coated fabric using Differential Scanning Calorimetry (DSC) and Thermogravimetric Analysis (TGA) for assessing its heat resistance. The shelf-life of the selected coated fabric was assessed by evaluating the residual strength (tensile and bursting), measured by subjecting it to accelerated and natural weathering tests. A special device was fabricated to carry out natural weathering test. Statistical analysis was performed at 95\% significance level to estimate the actual strength (tensile and bursting) loss upon weathering.

\section{INTRODUCTION}

Coated textiles are produced with a surface treatment of polymeric materials that are homogeneous in structure and various textile forms; woven, knit or nonwoven, are utilized as the substrate (Masteikaite \& Saceviciene, 2005). The polymer coating must be adhered to the textile material and a blade like interval controls the thickness of the viscous polymer and subsequently, it is heated and the polymer gets cured (Mondal, 2008). The textile form and additives for coating used to be selected depending upon the intended application of the coated fabric. This kind of product has many improved properties and multiple advantages over the substrate textile material (Kos et al., 2014). Coating a textile substrate offers numerous benefits: (a) protecting the constituent yarns against different sources

(C) 2021 The Author(s). This is an open access article distributed under the terms of the Creative Commons Attribution License, which permits unrestricted use, distribution, and reproduction in any medium, provided the original author and source are credited. 
of damage (UV, abrasion, atmosphere); (b) proofing the material against rainwater and atmospheric moisture; (c) stabilizes the base fabric geometry; (d) facilitates in developing seams with heat/radio-frequency/adhesive sealing; and (e) alteration in the macro-mechanical behaviour, for example, tensile, tear and stab (Farboodmanesh et al, 2005; Cubric et al., 2017; Wang et al., 2013; Wang et al., 2012). Coated fabrics have gained applications in different areas; flexible membranes for civil structures, medical substrates, geotextiles, industrial fabrics and airbags. Nowadays, these materials have developed wide applicability in tents, due to creation of multifunctional features (flame resistant, waterproof, windproof, ultraviolet (UV) light protection and weather resistant) with more durability by very limited layers of coating.

Heavy textiles in form of tents provide protection from the rough environment to normal wet climatic conditions for thousands of years. Current trends in tent fabrics are; waterproof, windproof, flame retardant, and ultraviolet (UV) radiation protective and structurally stable for out-door environment applications and the functionality of fabrics needs to be altered, as per scenario (Van et al., 1998; Surdu et al., 2015). Apart from these functional properties of tents, fabrics should be printed with camouflage patterns as per background of terrains and areas e.g. olive green for the forest area. Coated fabrics used for fabrication of tents are generally heavy and possess weight normally in the range from $\sim 300-650 \mathrm{~g} / \mathrm{m}^{2}$. Figure 1 shows the different compact weave designs of fabrics used for developing the coated fabrics for tents. Comapct woven strctures offer lightweight, waterproof, breathable, UV resistant tent (Saravanan, 207; Das et al., 2010). These densely woven structures possess small pore sizes $(\sim 30-40$ $\mu \mathrm{m}$ ) for trappping of functinoal coated mateartial like thermoplastic polyurethane (TPU), polyvinyl chloride (PVC), or flourocarbon etc and facilitate in higher degree of adhesion.
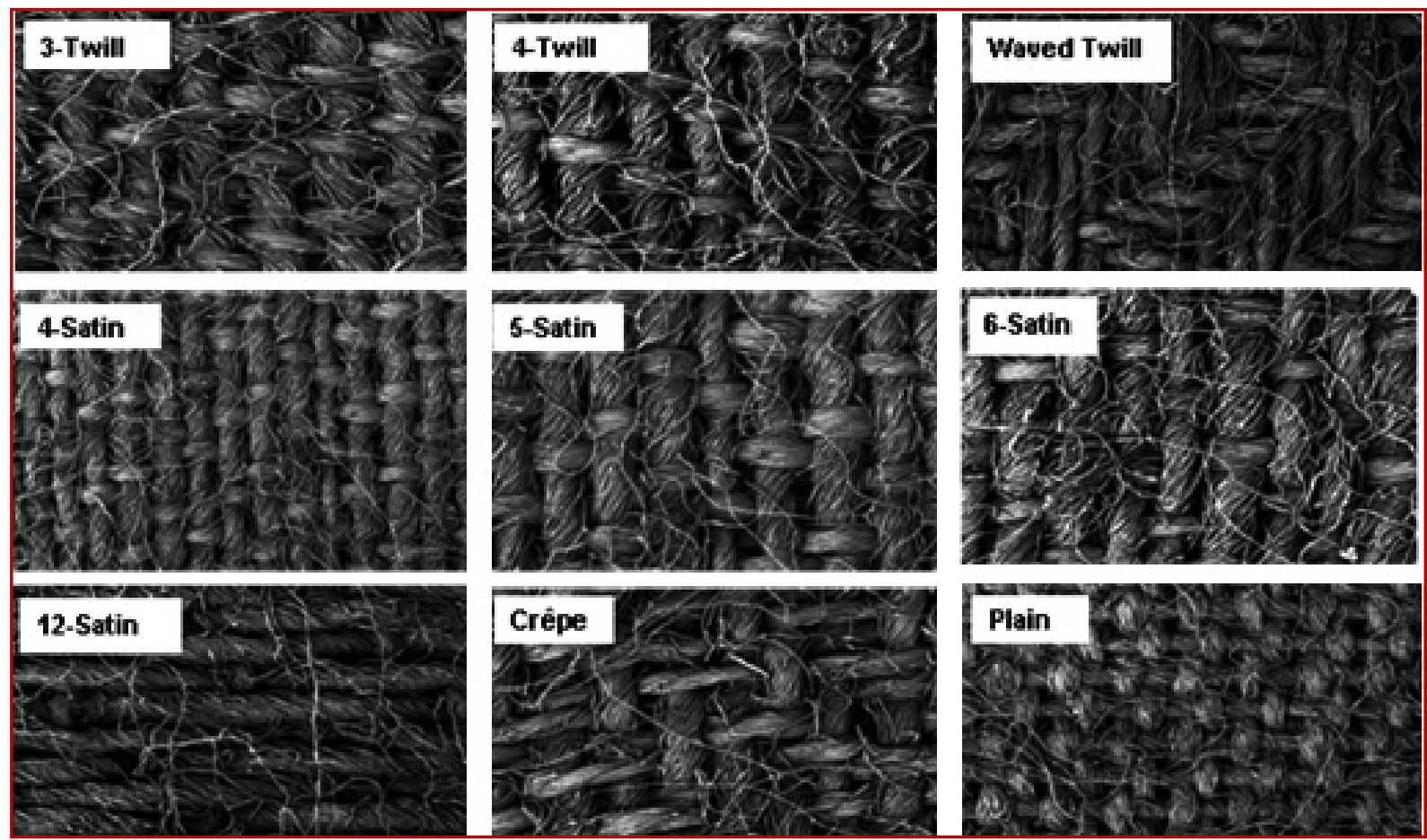

Figure 1: Microscopic image of various woven fabric structures used in tent (Matteo \& Alessandro, 2014)

Tents are preferably used by the military as temporary shelter, due to their relatively quick setup and take down times, as oppose to the traditional shelters. Many industries have emerged in response to popularity and huge requirements of the tents of all shapes and sizes, catering to small or large soldier groups in the extreme heat or cold and in all temperatures in between. There are several drawbacks associated with typical tents, as these are heavy, unwieldy and difficult to erect due to the inclusion of essentially rigid poles, which are used as the frame. In response to these poised challenges, textile industries are engaged in developing new materials to fabricate tents, that will substitute some or all the rigid poles with inflatable frames and sections (Mills, 2011).

Inflatable military tent (IMT) essentially comprises of four components: (a) canopy (b) beam (c) ground sheet and (d) compressor. The canopy fabric is the crucial component and is subjected to out-door environmental exposure, hence necessitates the various functional features to provide protection to the soldiers living inside. Very 
rare literature is available about the technical details of the materials and technology adopted in the preparation of the canopy fabric of the IMT for forest area. Hence, this research initiative was pursued for developing the state-ofthe-art material and its technology from indigenous source for preparation of canopy fabric to meet the urgent need of soldiers. The IMT for forest area will be fabricated with the new material and will be explored for assessing its suitability to replace the existing heavy weight tents. Apart from that, the existing tents possess limited shelf-life of five years, hence special grade of thermoplastic polyurethane (TPU) and the plasticized PVC were selected for coating in this new material development work to improve the shelf-life to ten years (minimum).

\section{EXPERIMENTAL}

\subsection{SAMPLE PREPARATION}

Two varieties of cover fabrics are developed with thermoplastic polyurethane (TPU) coating on Nylon fabrics (Nylon 6 and Nylon 6,6) and are prepared with olive green (OG) colour. The grey fabrics are first treated with 35\% solution of ECCOSHIELD® N-100 by pad-dry-cure method for providing flame retardancy and subsequently, dyed in OG colour. The olive green colour is developed by dyeing with acid dye (Orco Nylosol ${ }^{\mathrm{TM}}$ : Green C3G 200\%). The coating of polyurethane (40\%-TPU,7.5\%- $\mathrm{TiO}_{2}$ and 3\%-antioxidant) is carried out by solution coating method by using ethyl acetate as solvent with coating add-on of $15 \%$ on Nylon 6 and Nylon 6,6 fabrics. The technical parameters and test standards followed for evaluation of the functional parameters of grey fabrics are reported in Table 1.

Table 1: Technical parameters of the Nylon grey fabrics

\begin{tabular}{|c|c|c|c|}
\hline Fabric Parameters & Nylon 6 & Nylon 6,6 & Test Standards \\
\hline Ends/inch and Picks/inch & 66 and 44 & 53 and 48 & IS: 1963 \\
\hline Mass $\left(\mathrm{g} / \mathrm{m}^{2}\right)$ & 211.0 & 234.0 & IS : 7016 Pt-I \\
\hline Weave & Plain & Ripstop & Visual \\
\hline $\begin{array}{c}\text { Count of yarn (denier) } \\
\text { Warp } \\
\text { Weft }\end{array}$ & $\begin{array}{l}558.6 \\
564.5\end{array}$ & $\begin{array}{l}\text { Normal }=596.9 \& \mathrm{Rib}=2146.2 \\
\text { Normal }=625.5 \& \mathrm{Rib}=2280.0\end{array}$ & IS: 7703 Pt-I \\
\hline $\begin{array}{c}\text { Tenacity }(\mathrm{g} / \mathrm{d}) \\
\text { Warp } \\
\text { Weft }\end{array}$ & $\begin{array}{l}5.6 \\
4.9\end{array}$ & $\begin{array}{l}\text { Normal }=5.8 \& \mathrm{Rib}=5.2 \\
\text { Normal }=5.1 \& \mathrm{Rib}=4.5\end{array}$ & $\begin{array}{l}\text { IS: } 4910 \text { Pt-II } \\
\text { and } \\
\text { IS: } 7703 \text { Pt-I }\end{array}$ \\
\hline $\begin{array}{l}\text { Breaking strength (Kgf): } \\
5 \times 20 \mathrm{~cm} \text { between grips }\end{array}$ & $\begin{array}{l}\text { Warp - } 275.3 \\
\text { Weft - } 240.2\end{array}$ & $\begin{array}{l}\text { Warp - } 408.9 \\
\text { Weft - } 376.6\end{array}$ & IS : 7016 Pt-II \\
\hline $\begin{array}{c}\text { Breaking elongation } \%: 5 \\
\text { x } 20 \mathrm{~cm} \text { between grips }\end{array}$ & $\begin{array}{l}\text { Warp - } 43.0 \\
\text { Weft - } 32.8\end{array}$ & $\begin{array}{l}\text { Warp - } 39.1 \\
\text { Weft - } 38.5\end{array}$ & IS : 7016 Pt-II \\
\hline
\end{tabular}

One more cover fabric is developed with polyvinyl chloride (PVC) coating on Polyester fabric and is prepared with olive green (OG) colour. The coating of PVC is carried out by solution coating method by using Tetrahydrofuran (THF) as solvent with coating add-out with add-on of 60\%. The technical parameters and the test standards followed for evaluation of these parameters of the polyester grey fabric is reported in Table 2 . The grey fabric is first treated with $10 \%$ solution of ECCOSHIELD ${ }^{\mathrm{TM}}$ PE-100 by pad-dry-cure method for providing flame retardancy and subsequently, dyed in OG colour before PVC coating. The olive green colour is developed by dyeing with disperse dye (Orcocilacron ${ }^{\mathrm{TM}}$ ).

Table 2: Technical parameters of the Polyester grey fabric

\begin{tabular}{|c|c|c|}
\hline Fabric Parameters & Cover & Test Standards \\
\hline Ends/inch and Picks/inch & 56 and 54 & IS: 1963 \\
\hline Mass $\left(\mathrm{g} / \mathrm{m}^{2}\right)$ & 189.7 & IS : 7016 Pt-I \\
\hline Weave & Plain & Visual \\
\hline $\begin{array}{c}\text { Count of yarn (denier) } \\
\text { Warp and Weft }\end{array}$ & 488.6 and 474.5 & IS: 7703 Pt-I \\
\hline
\end{tabular}

International Journal of Research -GRANTHAALAYAH 
Development of Specialty Coated Fabrics for Canopy of Inflatable Military Tent (IMT) for Forest Area

\begin{tabular}{|c|c|c|}
\hline $\begin{array}{l}\text { Tenacity }(\mathrm{g} / \mathrm{d}) \\
\text { Warp and Weft }\end{array}$ & 5.1 and 4.8 & $\begin{array}{c}\text { IS: } 4910 \text { Pt-II and } \\
\text { IS: } 7703 \text { Pt-I }\end{array}$ \\
\hline Breaking strength (Kgf) : $5 \times 20 \mathrm{~cm}$ between grips & $\begin{array}{l}\text { Warp - } 203.1 \\
\text { Weft - } 198.2\end{array}$ & IS : 7016 Pt-II \\
\hline Breaking elongation $\%: 5 \times 20 \mathrm{~cm}$ between grips & $\begin{array}{l}\text { Warp }-33.0 \\
\text { Weft }-32.8\end{array}$ & IS : 7016 Pt-II \\
\hline
\end{tabular}

\section{EVALUATION}

\subsection{FUNCTIONAL FEATURES OF COATED FABRICS}

The mass $\left(\mathrm{g} / \mathrm{m}^{2}\right)$ of coated fabrics was measured following the IS: 1964 standard. Fabric thickness (mm) values of coated fabrics were measured at $200 \mathrm{~g} / \mathrm{cm}^{2}$ pressure according to the test standard IS: 7702. Shirley Stiffness Tester was used for determining the stiffness of coated fabrics according to BS: 3356 standard. Breaking strength (Kgf) and elongation\% of the coated fabrics were measured, following the IS: 7016 Pt-II test standard, by utilizing INSTRON Tensile Tester. The coated specimens for tear test were prepared according to cut slit method (MIL-C21189). For cut slit tear testing, coated fabric samples were cut with dimensions of $102 \mathrm{~mm}$ (4") width and $152 \mathrm{~mm}$ (6") length having a $32 \mathrm{~mm}\left(1 \frac{1 / 4}{\prime \prime}\right)$ wide razor cut slit across the centre of sample at right angle to the longest dimension. Bursting strength of coated fabrics was tested, referring the ASTM D 3786 M-18 standard, in the Diaphragm Bursting Strength Tester. Ten tests were carried out for tensile, tear and bursting test for measurement of the mean value. The coated fabrics were subjected to one lakh cycles of flexing in De-Mattia Flex tester according to the standard IS: 7016 Pt-IV.

Water proofness (water pressure of $30 \mathrm{~cm}$ for 30 minutes) and oil repellency of the coated fabrics were measured by using IS: 7016 Pt-VII and BS: UK/SC/3346 G test standards respectively. The flame retardancy of the coated fabrics was evaluated by referring the standard BS 3119 and specimen size and observation was made as per BS 5438-2B. UV radiation protection of coated fabrics was measured by the SPF Analyzer (Model SPF-290AS Automated UV Transmittance, TLS-Te Lintelo Systems) and the transmission\% of UV light (UV-A and UV-B) in the wavelength range of $290-400 \mathrm{~nm}$ was evaluated. The instrument automatically converts the transmission $\%$ to ultraviolet protection factor (UPF) with its installed software (Das, 2010; Das \& Hati, 2011). The coated fabrics were undergone accelerated ageing by following both the simulated cold and hot environmental conditions. The fabric specimens were subjected to resistance to low temperature at $-40^{\circ} \mathrm{C}$ for 06 hours and temperature of $70^{\circ} \mathrm{C} \pm 1^{\circ} \mathrm{C}$ for 168 hours refereeing to standards IS: 12718 and IS: 7016 Pt-VIII respectively in conditioning chamber. Colour fastness to washing and light was measured for these coated fabrics, according to standards IS: 687 and IS: 2454 respectively and the objective of evaluation of such features is that the specific component of IMT used to get exposed to open environmental conditions. The coated fabrics were treated in Oven at temperature of $60^{\circ} \mathrm{C}$ for 15 minutes to access blocking by following BS: 3424 Method 13 standard.

\subsection{THERMAL CHARACTERIZATION}

DSC and TGA was employed to monitor the thermal transition behaviour (melting and its energy association) and weight loss and degradation respectively, of the coated Nylon 6, 6 fabric. DSC and TGA profiles of coated fabric were traced by the Universal V4.7A TA Instrument, in a temperature range between $30-400^{\circ} \mathrm{C}$ with a heating rate of $10^{\circ} \mathrm{C} / \mathrm{min}$, under $\mathrm{N}_{2}$ atmosphere (Sinha et al., 2014).

\subsection{ASSESSMENT OF HYDROPHOBICITY}

The angle of contact and sliding of the water drop falling over the TPU coated Nylon 6, 6 fabric surface was measured in the Goniometer instrument for assessing the hydrophobicity. 


\subsection{ESTIMATION OF SHELF-LIFE OF MATERIALS}

The shelf-life of the selected TPU coated Nylon 6, 6 fabric was predicted by assessing the strength (tensile and bursting) degradation of this material upon subjecting to natural and artificial weathering conditions (Zhang et al., 2018; Eichert, 1994; Sleiman et al., 2014; Toyoda \& Motohashi, 2005). The TPU coated Nylon 6, 6 fabric was exposed to out-door environment for two months (60 days) by fixing in the fabricated device and subsequently, the breaking strength and elongation\% and bursting strength was measured and compared with its same properties of unexposed state to assess the extent of degradation. The fabricated device was prepared in a rectangular shape with $45^{\circ}$ inclination, such that the coated fabric installed in the device will exactly follow the same inclination during its out-door environmental exposure (Figure 2) and the device has provision of stretching at the top, due to larger width slot and screw arrangement associated with the fixing rod inserted in the installed fabric's loop, to apply the requisite pretension during exposure. The frame structure of the device (width- $40 \mathrm{~cm}$ and length $-100 \mathrm{~cm}$ ) was prepared with stainless steel to avoid rusting during out-door environmental exposure. As the natural weathering is generally carried out for a prolonged period, hence the accelerated weathering was carried out artificially by simulating the out-door environmental exposure conditions (UV radiation and elevated temperature with higher stress), within a limited time (Zhang et al., 2010). The TPU coated Nylon 6, 6 fabric was given xenon $\operatorname{arc}\left(1.10 \mathrm{~W} / \mathrm{m}^{2}\right.$ or $\left.420 \mathrm{~nm}\right)$ exposure in Q-SUN xenon test chamber for duration of 100 hours in accordance with standard: ISO 105: B02:2014 and subsequently, the breaking strength and elongation $\%$ and bursting strength was evaluated to assess the extent of deterioration. This xenon arc light matches the full spectrum of sunlight, which simulates the damage caused by natural sunlight and this tester can reproduce the damage that occurs over months or years in out-door environmental exposure within few days or weeks.

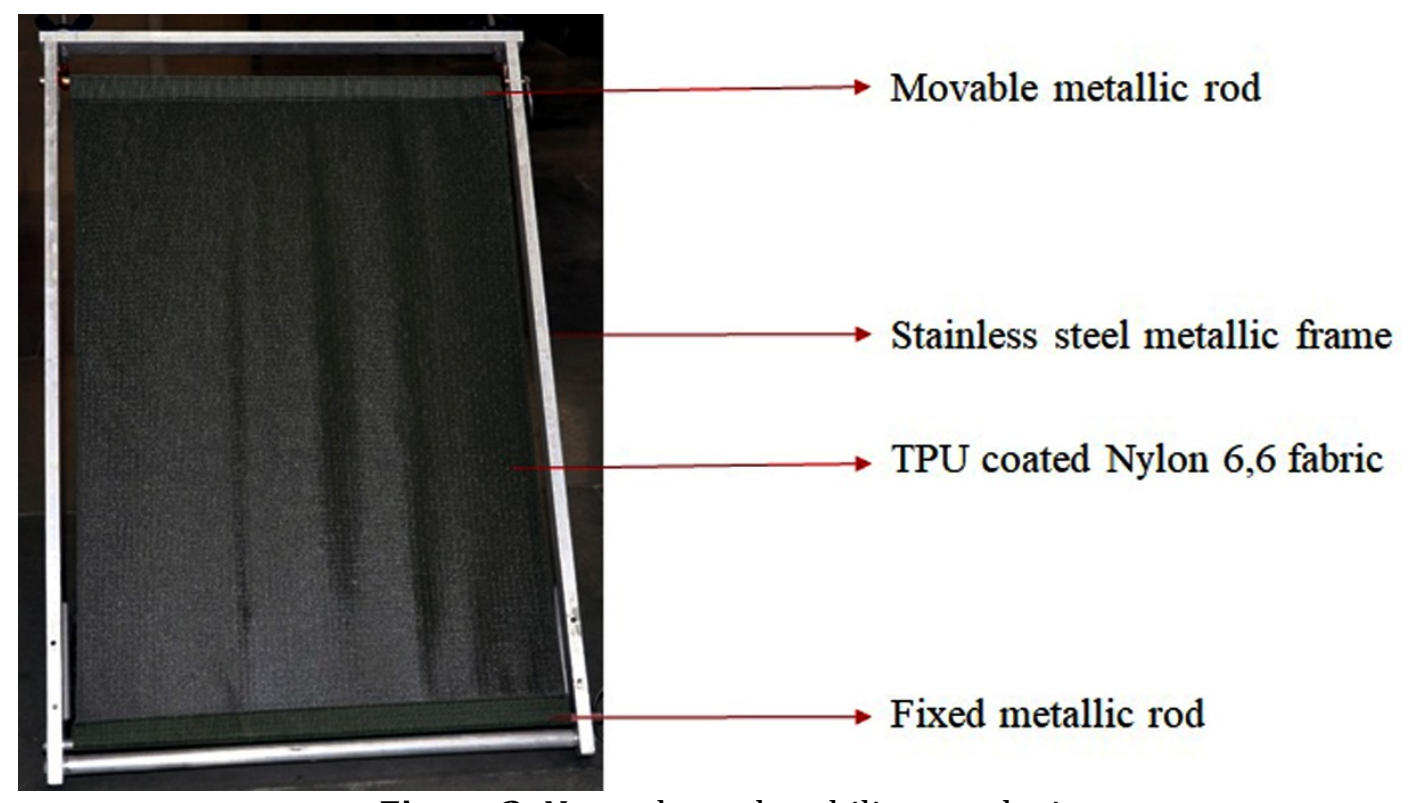

Figure 2: Natural weatherability test device

\subsection{STATISTICAL ANALYSIS}

Population behaviour is predicted from the sample behaviour, by involving the probability factor, which is statistically called as significance level. Hypothesis testing is followed for comparison between two populations parameter, based on the mean values of the sample parameter. The brief hypothesis testing procedure is reported below (for sample strength, $n<30$ )

Ho: Null hypothesis: No difference between the sample means

$\mathrm{H}_{1}$ : Alternate hypothesis: $\overline{x_{1}} \geq \overline{x_{2}}$, where $\overline{x_{1}}, \overline{x_{2}}$ are sample means 
Development of Specialty Coated Fabrics for Canopy of Inflatable Military Tent (IMT) for Forest Area

The $t$ statistics is calculated as follows:

$$
t=\frac{\left|\overline{x_{1}}-\overline{x_{2}}\right|}{S E \sqrt{\frac{1}{n_{1}}+\frac{1}{n_{2}}}}
$$

$S E$ - Estimated standard deviation of the distribution of differences between independent sample means and $n_{1}$, $n_{2}$ are number of samples

$$
S E=\sqrt{\frac{\left(n_{1}-1\right) s_{1}^{2}+\left(n_{2}-1\right) s_{2}^{2}}{n_{1}+n_{2}-2}}
$$

$\mathbf{s}_{1}, s_{2}$ are sample standard deviations.

The statistical inference is drawn at 95\% confidence level with single tail test. The comparison of $t$ value between the calculated vs. statistical table (degree of freedom $d f=n_{1}+n_{2}-2$ ) is carried out and when the calculated $t$ value was found higher than the other, then alternate hypothesis was accepted (Das et al., 2013). This statistical significance test was performed for assessment of deterioration of breaking and bursting strength of TPU coated Nylon 6, 6 fabric after subjecting to accelerated and natural weathering conditions. The breaking and bursting strength measured after exposure to accelerated and natural weathering was compared with the un-exposed fabric's same properties using this referred statistical analysis to draw the conclusion about the breaking and bursting strength difference, at 95\% confidence level. Most importantly, the shelf-life of the material was predicted based on the assessment of influence of accelerated and natural weathering.

\section{RESULTS AND DISCUSSIONS}

\subsection{FUNCTIONAL FEATURES OF THE COATED FABRICS}

The canopy of IMT for forest area is the specific component, which is exposed to the open environmental condition, hence needs to be flame retardant, waterproof, wind proof, oil repellent, resistant to accelerated weathering, colour fastness to washing and light and protective to ultraviolet light to serve for the intended purpose for a prolonged period. Apart from that, it should have adequate mechanical properties (breaking strength and elongation \%, tear strength, bursting strength and resistant to flexing) to meet the essential requirements. Looking at the requirements of various essential functional features according to the deployable condition and packaging of the IMT for forest area, the various properties were evaluated for the three varieties of developed coated fabrics. The mechanical properties of the coated fabrics used for canopy of IMT are highly important feature, as the service life and reinforcement of the structure is decided by this factor and the various evaluated mechanical parameters of the coated fabrics are presented in Table 3. The mass, thickness and bending length of the three varieties of developed coated fabrics are found to be in the acceptable limit (mass: 250- $320 \mathrm{~g} / \mathrm{m}^{2}$; thickness: $0.3-0.6 \mathrm{~mm}$ and bending length: 30-45 mm) for easier fabrication, packaging and radio frequency (RF) sealing. It was observed from Table 3 that the breaking strength, tear strength and bursting strength of the TPU coated Nylon 6,6 is the highest followed by TPU coated Nylon 6 and PVC coated Polyester and this trend of observation can be ascribable to the decreasing order of breaking strength and elongation $\%$ of their substrate basic fabrics. The coated fabrics displayed improvement in breaking strength compared to their respective substrate basic fabrics, in the range of $6.5 \%$ to $10 \%$ approximately. All the coated fabrics displayed excellent resistance to flexing with observation of no change from their original states and this technical feature is the most crucial parameter for the IMT, as the material will be very frequently prone to folding and unfolding during deployment and storage, after getting deflated. 
Biswa Ranjan Das, Dasaradhan Bharathi, Deepak Kumar Yadav, Manoj Kumar Singh, Thako Hari Goswami, and Namburi Eswara Prasad

Table 3: Mechanical properties of coated fabrics: Nylon 6, Nylon 6, 6 and Polyester

\begin{tabular}{|c|c|c|c|}
\hline Test Parameters & Nylon 6 & Nylon 6,6 & Polyester \\
\hline $\operatorname{Mass}\left(\mathrm{g} / \mathrm{m}^{2}\right)$ & 262.17 & 305.29 & 308.3 \\
\hline Thickness (mm) & 0.39 & 0.54 & 0.28 \\
\hline $\begin{array}{l}\text { Bending Length (mm) } \\
\text { Warp and Weft }\end{array}$ & 37.1 and 36.3 & 31.75 and 41.63 & 33.9 and 27.1 \\
\hline Breaking strength (Kgf) & $\begin{array}{l}\text { Warp - } 297.65 \\
\text { Weft - } 260.51\end{array}$ & $\begin{array}{l}\text { Warp - } 436.3 \\
\text { Weft }-399.2 \\
\end{array}$ & $\begin{array}{l}\text { Warp - } 223.0 \\
\text { Weft - } 215.3\end{array}$ \\
\hline Breaking elongation $\%$ & $\begin{array}{l}\text { Warp - } 43.06 \\
\text { Weft - } 31.90\end{array}$ & $\begin{array}{l}\text { Warp - } 39.3 \\
\text { Weft - } 38.4\end{array}$ & $\begin{array}{l}\text { Warp - } 33.51 \\
\text { Weft - } 32.90\end{array}$ \\
\hline $\begin{array}{c}\text { Tear strength (Kgf) } \\
\text { Warp and Weft }\end{array}$ & 71.15 and 59.40 & 75.76 and 64.39 & 46.57 and 39.47 \\
\hline Bursting strength (Kgf/cm²) & 65.25 & 70.42 & 53.28 \\
\hline $\begin{array}{l}\text { Resistance to damage by flexing } \\
\text { after } 1,00,000 \text { cycles }\end{array}$ & $\begin{array}{l}\text { No apparent change } \\
\text { from the original }\end{array}$ & $\begin{array}{l}\text { No apparent change } \\
\text { from the original }\end{array}$ & $\begin{array}{l}\text { No apparent change } \\
\text { from the original }\end{array}$ \\
\hline
\end{tabular}

The other essential functional features of the three varieties of coated fabrics are presented in Table 4. The degradation of canopy fabric is mainly because of penetration of rain water and viscous fluids and this necessitates the evaluation waterproofness and oil repellency. The TPU and PVC coating for the fabrics found adequate in offering water waterproofness and oil repellency and this justified that the respective add-on\% considered for different treatment is very suitable. The flame retardancy treatment carried out for the three varieties of coated fabrics offered the adequate flame retardancy. As the canopy fabric of IMT for forest area is the main exposed protective barrier, the inadequate flame retardancy will put the soldier's life in danger in case of any fire hazards, which is quite frequent in forest areas. All the coated fabrics found offering excellent UV light protection and the PVC coated Polyester showed the highest value of UPF followed by TPU coated Nylon 6, 6 and TPU coated Nylon 6 fabrics. The heavy addon (50\%) of PVC coating offered complete blockage to UV light (A and B) passage and resulted the highest UPF value of 35134.21. Though the TPU add-on (15\%) is same for both Nylon 6, 6 and Nylon 6 fabrics, but the observed UPF is higher for the earlier, due to its compact weave structure. Nylon 6, 6 fabric was prepared with rip stop weave design as oppose to plain weave of Nylon 6 fabric and accordingly, the observation of their respective UPF values (3516.91 and 2837.74). All the three varieties of coated fabrics showed excellent resistance to both the low and high temperatures and this indicated that the developed materials have potential to be used in glacier region and desert area respectively. The canopy is exposed to outside environment, hence the washing and light fastness of the developed coated fabrics were evaluated and it was found that the three varieties of coated fabrics displayed excellent washing and light fastness. The packaging and storage of IMT needs evaluation of blocking behaviour to avoid sticking between coating layers and no blocking was observed for the three varieties of coated fabrics. Hence, based on the evaluated mechanical parameters and other functional features, all these developed coated materials were treated as suitable for canopy fabric of IMT for forest area.

Table 4: Essential functional properties of coated fabrics: Nylon 6, Nylon 6, 6 and Polyester

\begin{tabular}{|c|c|c|c|}
\hline Test Parameters & Nylon 6 & Nylon 6, 6 & Polyester \\
\hline $\begin{array}{c}\text { Water proofness } \\
\text { Percolation }(\mathrm{ml}) \\
\text { Wetting of the outer surface }\end{array}$ & $\begin{array}{l}\text { No percolation } \\
\text { No wetting }\end{array}$ & $\begin{array}{l}\text { No percolation } \\
\text { No wetting }\end{array}$ & $\begin{array}{l}\text { No percolation } \\
\text { No wetting }\end{array}$ \\
\hline Oil repellency & No penetration, $10 / 10$ & No penetration, $10 / 10$ & No penetration, $10 / 10$ \\
\hline Flame Retardancy & $\begin{array}{l}\text { After Flame (Sec) - Nil } \\
\text { After Glow (Sec) - Nil } \\
\text { Flame Debris - No } \\
\end{array}$ & $\begin{array}{l}\text { After Flame (Sec) - Nil } \\
\text { After Glow (Sec) - Nil } \\
\text { Flame Debris - No } \\
\end{array}$ & $\begin{array}{c}\text { After Flame (Sec) - Nil } \\
\text { After Glow (Sec) - Nil } \\
\text { Flame Debris - No } \\
\end{array}$ \\
\hline $\begin{array}{l}\text { UV radiation protection } \\
\text { Transmission } \% \\
\text { UPF }\end{array}$ & $\begin{array}{c}\text { UV-A: } 0.09 \\
\text { UV-B: } 0.04 \\
2837.74\end{array}$ & $\begin{array}{c}\text { UV-A: } 0.07 \\
\text { UV-B: } 0.01 \\
3516.91\end{array}$ & $\begin{array}{c}\text { UV-A: } 0.00 \\
\text { UV-B: } 0.00 \\
35134.21\end{array}$ \\
\hline
\end{tabular}


Development of Specialty Coated Fabrics for Canopy of Inflatable Military Tent (IMT) for Forest Area

\begin{tabular}{|c|c|c|c|}
\hline $\begin{array}{c}\text { Resistance to low temperature } \\
\text { at }-40^{\circ} \mathrm{C}\end{array}$ & $\begin{array}{c}\text { No apparent change } \\
\text { from the original }\end{array}$ & $\begin{array}{c}\text { No apparent change } \\
\text { from the original }\end{array}$ & $\begin{array}{c}\text { No apparent change } \\
\text { from the original }\end{array}$ \\
\hline $\begin{array}{c}\text { Resistance to high temperature } \\
\text { at } 70^{\circ} \mathrm{C} \pm 1^{\circ} \mathrm{C}\end{array}$ & $\begin{array}{c}\text { No apparent change } \\
\text { from the original }\end{array}$ & $\begin{array}{c}\text { No apparent change } \\
\text { from the original }\end{array}$ & $\begin{array}{c}\text { No apparent change } \\
\text { from the original }\end{array}$ \\
\hline $\begin{array}{c}\text { Colour fastness to washing } \\
\text { (change in colour rating) }\end{array}$ & 5 & 5 & 5 \\
\hline $\begin{array}{c}\text { Colour fastness to light (change } \\
\text { in colour rating) }\end{array}$ & 6 & 6 & 6 \\
\hline Blocking & No blocking & No blocking & No blocking \\
\hline
\end{tabular}

The TPU coated Nylon 6, 6 fabric was found the most suitable material among the three varieties of coated fabrics prepared for canopy of IMT because of its superior mechanical properties (breaking strength, tear strength and bursting strength) compared to the other coated fabrics. Apart from this, Nylon 6, 6 coated fabric had shown excellent resistance to flexing and accelerated ageing and very good colour fastness to washing and light, hence it was predicted that the material's shelf-life will be appreciably higher. Apart from that the selected coated fabric showed waterproofness and higher water contact angle of $121^{\circ}$, as shown in Figure 3 and also displayed the lower sliding angle $\left(12^{\circ}\right)$, which in combination, offered synergetic effect with other superior functional features to improve the durability and shelf-life of the material. The root cause of degradation of canopy fabric developed with TPU coating is the rainwater penetration. Due to higher water contact angle and lower sliding angle, the rain drop falling over the fabric will reside for short time and it will quickly slip down. The feature of waterproofness with higher water contact angle will offer very negligible chance for rain drop falling over the coated fabric to penetrate. This selected fabric possesses the superior functional properties compared to the contemporary industrial grade textile materials used in tents. Hence, this material is treated as the novel material and selected for fabrication of IMT for forest area.

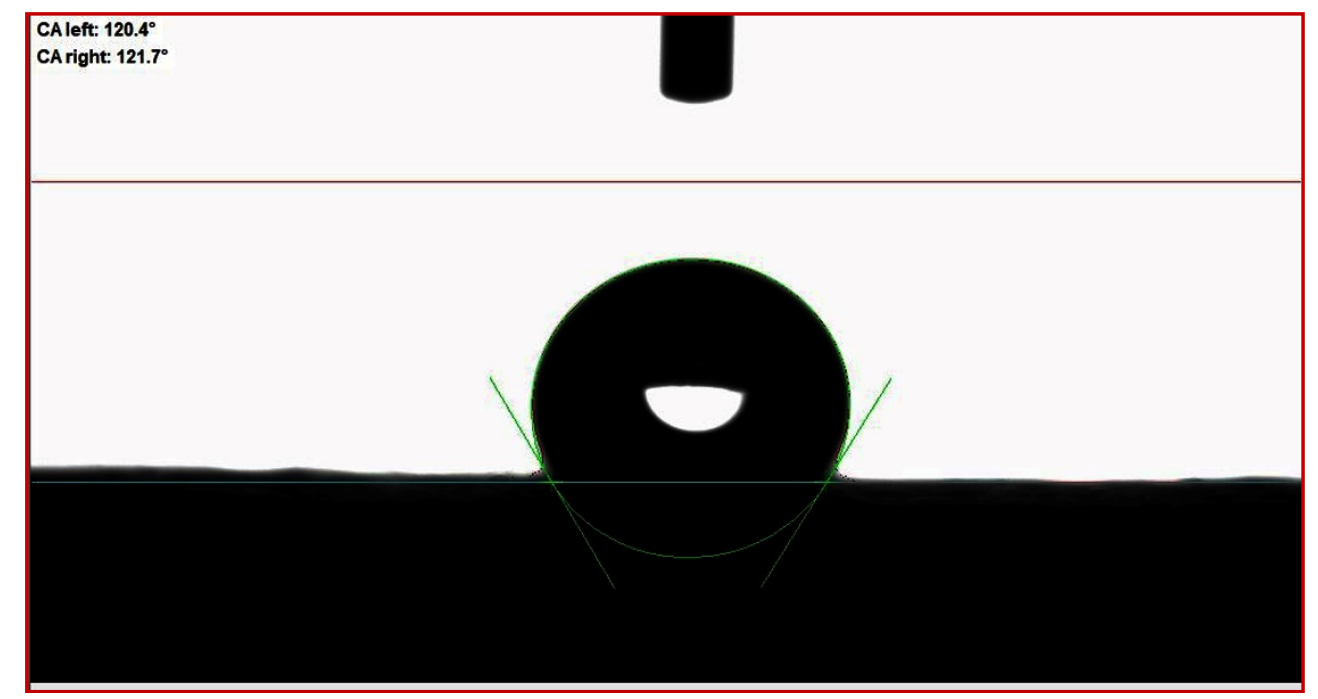

Figure 3: Water contact angle observed with TPU coated Nylon 6, 6 fabric

\subsection{THERMAL BEHAVIOUR OF COATED FABRIC}

The melting temperature of the substrate basic Nylon 6, 6 fabric was measured to be $259.81^{\circ} \mathrm{C}$ (Figure 4). The crystallinity\% of the fabric was also calculated from the DSC profile by comparing with the energy (196 J/g) associated with the melting of $100 \%$ crystalline Nylon 6, 6 fabric (Brandrup et al., 1999). The energy associated with melting of the Nylon 6,6 fabric was calculated to be $177.94 \mathrm{~J} / \mathrm{g}$ and the crystallinity was calculated to be $90.79 \%$. Hence, it was understood that the selected coated Nylon 6, 6 fabric is developed with substrate of highly crystalline material and the same is also reflected in the breaking strength of the substrate basic fabric (Table 1). Thermal stability of coated Nylon 6, 6 fabric was investigated and found that the weight loss due to degradation of the constituent polymer started at $350^{\circ} \mathrm{C}$ (Figure 5). The coated fabric was intended to be used as canopy of IMT for the 
forest area, where the material will be subjected to a much lower temperature as compared to the melting temperature of substrate basic fabric and degradation temperature of this coated fabric. Hence, the selected material was considered appropriate to resist the thermal stress to be exerted during its application in forest area.

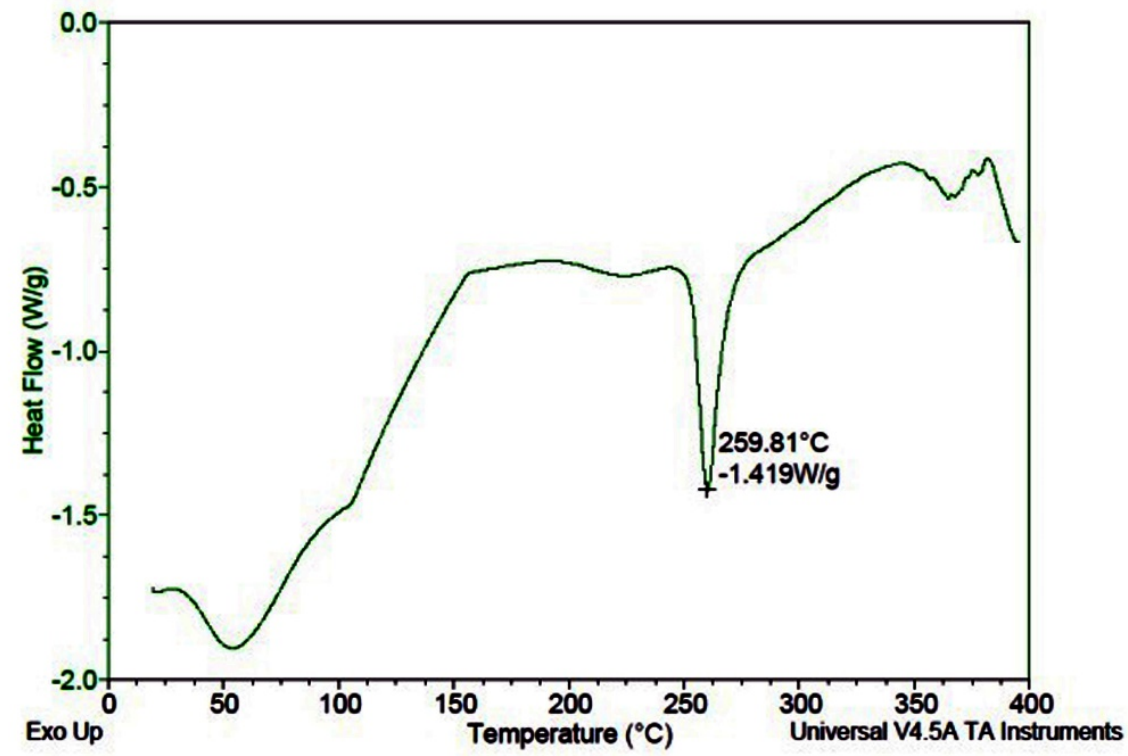

Figure 4: DSC profile of the substrate basic Nylon 6, 6 fabric

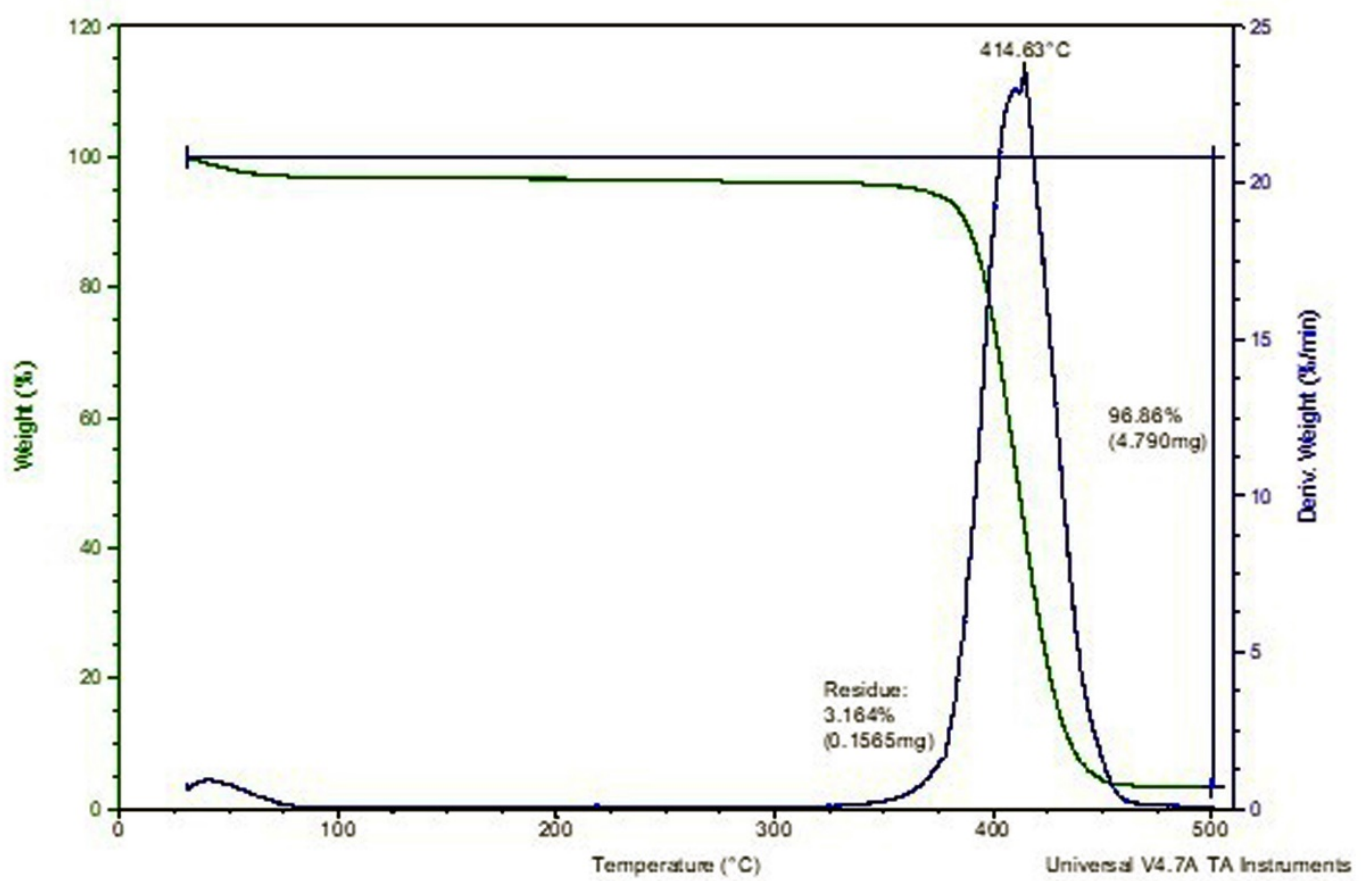

Figure 5: TGA profile of TPU coated Nylon 6, 6 fabric

\subsection{ASSESSMENT OF SHELF-LIFE}

The coated Nylon 6, 6 fabric was subjected to natural and accelerated weathering effect and the material showed excellent resistance with no strength loss, at 95\% statistical significance level. Though, there was decrease in breaking strength and elongation $\%$ in terms of absolute value in both the case of natural and accelerated weathering (Table 5), but this difference was found statistically insignificant. Along with the tensile behaviour, the bursting 
strength was also found to be unaffected, even though subjected to weathering (accelerated and natural). The slight difference in the absolute values of bursting strength, between the un-exposed state and after subjecting to weathering (accelerated and natural), was found statistically insignificant. Hence, it was predicted that the selected coated material will display a shelf-life of more than or equivalent to ten years and service life of five years, as the weathering effect found very poor adverse/degradation impact.

Table 5: Breaking strength and elongation\% and bursting strength of TPU coated Nylon 6, 6 fabric (unexposed, artificial weathered and natural weathered)

\begin{tabular}{|c|c|c|c|}
\hline Treated fabric & Breaking strength (Kgf) & Elongation\% & Bursting strength (Kgf/cm $\left.{ }^{2}\right)$ \\
\hline Un-exposed fabric & & & $70.42(3.17)$ \\
Warp & $436.33(20.91)$ & $39.3(1.75)$ & \\
Weft & $399.16(14.41)$ & $38.4(1.49)$ & \\
\hline Artificial weathering & & & $68.54(3.25)$ \\
Warp & $328.06(20.47)$ & $39.1(1.32)$ & \\
Weft & $394.74(13.97)$ & $37.9(1.74)$ & $68.32(3.32)$ \\
\hline Natural weathering & $422.29(23.64)$ & $38.9(0.66)$ & \\
Warp & $390.15(16.85)$ & $37.7(1.30)$ & \\
Weft &
\end{tabular}

* Values in the parenthesis indicates standard deviation

\section{CONCLUSIONS AND RECOMMENDATIONS}

This research programme has successfully developed and established the technology and material for preparation of coated fabric for canopy of IMT for forest area, which is superior to any contemporary material existing across the globe. The research findings will assist in the development of very lightweight and durable coated fabrics for utilizing as the canopy (out-door exposed component) of various tents for both defence and civilian applications. The following conclusions are drawn from the present research work:

The TPU coated Nylon 6, 6 fabric was found as the most suitable material for canopy of IMT than the coated Nylon 6 and Polyester fabrics due to its superior mechanical properties (breaking strength, tear strength and bursting strength) and all these coated fabrics were prepared in OG colour to serve for forest area.

This selected TPU coated Nylon 6, 6 fabric was also found meeting the other essential functional feature requirements (waterproofness, oil repellency, flame retardancy, UV radiation protection, colour fastness to washing \& light and blocking) of canopy for IMT and most importantly, the fabric was developed with only $15 \%$ polyurethane add-on.

Statistical analysis was carried out at 95\% significance level and found that the accelerated and natural weathering test has very insignificant influence on the breaking and bursting strength of TPU coated Nylon 6, 6 fabric. The impact of accelerated weathering for 100 hours and natural weathering for 60 days on the selected coated fabric was found to be more over similar.

The selected canopy fabric (TPU coated Nylon 6,6) turn out as excellent UV radiation protective material (UPF $=3516.91$ ) and also meeting the required colour fastness to washing and light.

This TPU coated Nylon 6, 6 fabric had shown superior mechanical properties and other essential functional features and also displayed higher water contact angle with lower sliding angle and proven its potential as a novel material offering excellent resistance to UV radiation and weathering, hence it was predicted that the material will display minimum shelf-life and service life of 10 and 05 years respectively.

\section{SOURCES OF FUNDING}

This research received no specific grant from any funding agency in the public, commercial, or not-for-profit sectors. 
Biswa Ranjan Das, Dasaradhan Bharathi, Deepak Kumar Yadav, Manoj Kumar Singh, Thako Hari Goswami, and Namburi Eswara Prasad

\section{CONFLICT OF INTEREST}

The author have declared that no competing interests exist.

\section{ACKNOWLEDGMENT}

SASMIRA, Mumbai is deeply acknowledged for providing the testing facilities for evaluation of tensile strength \& elongation\% and bursting strength. Authors also thank Shri Mahesh Chaudhary, Dr. Kavita Aggarwal, Dr. Joy Chakraborty, Shri Lallan Saha, Shri Brij Kishore and Shri Ravi Singh of DMSRDE, DRDO, Kanpur, India for their support in various evaluation works. The authors acknowledge with profound thanks for the fabrication of natural weatherability test device by Shri Atul Saxena of DMSRDE. The authors are grateful to industry partners: M/s Kusumgar Corporates, Vapi, Gujarat; M/s Garware Technical Fibres, Pune, Maharastra and M/s Entremonde Polycoaters, Nashik, Maharastra for providing facilities for developing the coated fabrics.

\section{REFERENCES}

[1] Brandrup, J., Immergut, E.H. and Grulke, E.A. Polymer handbook. 4th edn. New York, USA: Wiley, 1999.

[2] Cubric,' I.S., Matkovic,' V.M.P., Skenderi, Z. and Tarbuk, A. Impact of substrate on water vapour resistance of naturally weathered coated fabrics, Textile Research Journal, 87(13), 2017, 1541-1553.

[3] Das, B.R., Ishtiaque, S.M., Rengasamy, R.S., Hati, S. and Kumar, A. Ultraviolet absorbers for textiles, Research Journal of Textile \& Apparel, 14(1), 2010, 42-52.

[4] Das, B.R. UV radiation protective clothing, Open Textile Journal, 3, 2010, 14-21.

[5] Das, B.R. and Hati, S. Engineered clothing and ultraviolet radiation, Asian Textile Journal, 20(1), 2011, 28-33.

[6] Das, B.R., Bhattacharjee. D., Kumar, K. and Srivastava, A. Thermo-physiological comfort characteristics of finedenier polypropylene fabrics, Research Journal of Textile \& Apparel, 17(1), 2013, 133-140.

[7] Eichert, U. Residual tensile and tear strength of coated industrial fabrics determined in long-time tests in natural weather conditions, Journal of Industrial Textiles, 23(4), 1994, 311-327.

[8] Farboodmanesh, S., Chen, J., Mead, J.L., White, K.D., Yesilalan, H.E., Laoulache, R. and Warner, S.B. Effect of coating thickness and penetration on shear behaviour of coated fabrics, Journal of Elastomers and Plastics, 37(3), 2005, 197-227.

[9] Kos, I, Schwarz, I.G. and Suton, K. Influence of warp density on physical-mechanical properties of coated fabric, Procedia Engineering, 69, 2014, 881-889.

[10] Masteikaite, $\mathrm{V}$ and Saceviciene, V. Study on tensile properties of coated fabrics and laminates, Indian Journal of Fibre \& Textile Research, 30(4), 2005, 267-272.

[11] Matteo, S. and Alessandro, C. Wearable electronics and smart textiles: A critical review. Sensors, 14(7), 2014, 11957-11992.

[12] Mills, D. Inflatable tent, Patent no. US20110253184A1, USA, 2011.

[13] Mondal, S. Phase change materials for smart textiles: An overview, Applied Thermal Engineering, 28(11-12), 2008, 1536-1550.

[14] Saravanan, D. UV protection textile materials, Autex Research Journal, 7(1), 2007, 53-62.

[15] Sinha, M.K., Das, B.R., Mishra, R., Ranjan, A., Srivastava, A. and Saxena, A.K. Study of electrospun polycarbosilane (PCS) nanofibrous web by needle-less technique. Fashion and Textiles, 1(2), 2014, 1-14.

[16] Sleiman, M., Kirchstetter, T.W., Berdahl, P., Gilbert, H.E., Quelen, S., Marlot, L., Preble, C.V., Chen, S., Montalbano, A., Rosseler, O., Akbari, H., Levinson, R. and Destaillats, H. Soiling of building envelope surfaces and its effect on solar reflectance-Part II. Development of an accelerated ageing method for roofing materials, Solar Energy Materials and Solar Cells, 122, 2014, 271-281.

[17] Surdu, L., Radulescu, I.R. and Nicula, G. Research for accomplishing multifunctional textiles for emergency shelters and other applications, Research \& Reviews: Journal of Chemistry, 4(4), 2015, 6-13.

[18] Toyoda, H. and Motohashi, K. The evaluation method for weatherability of membrane materials for architectural membrane structures. In: 10 DBMC international conference on durability of building materials and components, Lyon, France, 17-20 April 2005. 
[19] Van, X.W., England, M.E., Kuivinen, K.C. and Potter, J.J. A critical review of design and use of field tent shelters in Polar Regions, Polar Record, 34(189), 1998, 113-122.

[20] Wang, P., Sun, B and Gu, B. Comparison of stab behaviours of uncoated and coated woven fabrics from experimental and finite element analyses, Textile Research Journal, 82(13), 2012, 1337-1354.

[21] Wang, P., Sun, B. and Gu, B. Comparisons of trapezoid tearing behaviours of uncoated and coated woven fabrics from experimental and finite element analysis. Int J Damage Mech 2013; 22(4): 464-489.

[22] Zhang, Y., Zhang, Q., Zhou, C. and Zhou, Y. Mechanical properties of PTFE coated fabrics, Journal of Reinforced Plastics and Composites, 29(24), 2010, 3624-3630.

[23] Zhang, Y., Xu, J. and Zhang, Q. Advances in mechanical properties of coated fabrics in civil engineering, Journal of Industrial Textiles, 48(1), 2018, 255-271. 